\section{IJ\$ER}

ISSN: 2149-5939
International Journal of Social Sciences and Education Research

Online, http://dergipark.gov.tr/ijsser

Volume: 3(2), 2017

\title{
Ticaret Odalarının web sitesi aracılığıyla kamuyu aydınlatmaları üzerine bir araştırma ${ }^{1}$
}

\section{A research on how Chambers of Commerce inform public through web sites}

\author{
Salim Şengel2
}

\begin{abstract}
Received Date: $01 / 10 / 2016$
Accepted Date: 20 / 02 / 2017

$\ddot{O} z$

Ticaret odalarl, üyelerinin mesleki alandaki faaliyetlerinin bir düzen içinde yürümesini sağlamak ve kanunda belirtilen hizmetleri yürütmek için kurulmuş kamu kuruluşu niteliğinde melek kuruluşlarıdır. Ticaret siciline kayıtlı tacirler ile sanayiciler odalara üye olmak zorundadır. Üyeler oda kayıt ücreti ve yıllık aidat ödemeleri gerekir. Odalar ticari hayatın önemli bir aktörüdür ve bu görevi yerine getirirken önemli bir kaynak kullanımı da söz konusudur. Günümüzde, özel sektör ve kamu açısından kamuyu aydınlatma konusunda önlemler alınmış ve yasal zemine oturtulmuştur. Bu bağlamda kamu kurumu niteliğindeki ticaret odalarının kamuyu aydınlatmaları konusunda önemli araçlarından birisi de web siteleridir. Bu çalışmada ticaret odalarının mali ve faaliyet raporlarını web siteleri aracılığıyla kamuoyuna sunumu araştırllmış ve değerlendirmede bulunulmuştur.
\end{abstract}

Anahtar sözcükler: Kamuyu aydinlatma, web sitesi, Ticaret Odası

\begin{abstract}
Chambers of Commerce are professional public associations founded to enable their members carry on the occupational facilities in the order and perform the services specified in the regulations. Trade merchants registered and industrialists have been members of chambers. The members have to pay the registry fee of the chamber and yearly contribution. The chambers are important actors of the commercial life and while realizing this task, the use a great deal of funds. Today, precautions about disclosuring public from the respects of the private and public sectors and it has been settled on legal basis. In this context, the web sites of the chambers are one of the important tools in disclosuring the public. In this study, how The Chambers present the fiscal and operating reports via web sites was searched and evaluated.
\end{abstract}

Keywords: Disclosuring the Public, web sites, Chamber of Commerce

\section{Giriș}

Son yıllardaki hızlı teknolojik gelişme beraberinde bilginin hızla yayılmasını ve iletilmesi sağlamıştır. Bilgi çağına doğru hızla ilerlediğimiz günümüzde bu gelişmeleri yakalayabilen toplumlar ile gelişmelerden uzak kalan toplumlarla arasındaki farklarda hızla büyümektedir. Bu gelişmelere neden olan esas itibariyle bilgidir.

Son y1llardaki teknolojik gelişmeler baş döndürücü niteliktedir. Özellikle bilişim teknolojisindeki gelişmeler insan ve toplum yaşamında önemli değişimlere yol açmaktadır. Bilişim teknolojisindeki gelişmeler sayesinde bilgiye ulaşmak sorun olmaktan çıkmıştır. Bilgininde günümüzde en hızlı bir şekilde yayıldığg ve iletildiği ortam ise internet ortamı ve özellikle web siteleridir.

\footnotetext{
${ }^{1}$ ICSSER (2016 İstanbul) 2.Uluslararası Sosyal Bilimler \& Eğitim Araştırmaları Konferansında sözlü bildiri olarak sunulmuştur.

${ }^{2}$ Prof. Dr., Anadolu Üniversitesi, Eskişehir Meslek Yüksekokulu, Eskişehir, Türkiye, ssengel@anadolu.edu.tr
} 
Şengel, S. (2017). A research on how Chambers of Commerce inform public through web sites. International

Journal of Social Sciences and Education Research, 3(2), 644-656.

\section{Kamuyu aydınlatma}

Dünyada 1720'li yıllara kadar uzanan "kamuyu aydınlatma" kavramı 20. yüzyılın başlarına kadar yavaş bir gelişme göstermiştir. 1920'leri izleyen hızlı ekonomik gelişmeler ve ülkelerin ulusal ekonomilerini yönlendirmede yeni önlemler alma gayretleri kamuyu aydınlatma ilkesi üzerinde etkili olmuştur. Özellikle 1929 ekonomik krizinin ortaya çıkışı ve sermaye piyasasının çöküşünü izleyen 4 yıl içinde sermaye piyasasının gelişmesinde ve kamunun aydınlatılmasında köklü değişiklik yaratacak düzenlemeler yapılmıştır. (Tetik, Demirel, 2002:1) Kamuyu aydınlatma kavramının özünde, bir durumun açıklanması veya bir durum, olay veya faaliyet hakkında bilgi verilmesi olgusu yatmaktadır. (Eroğlu, 2003:7) Kamuya açıklanan bilgilerde genel olarak aşağıda belirtilen konuların olması gerekmektedir (Kepekçi, 1983:59)

1. Kamuya açıklanan bilgiler ihtiyaç duyulan önemli bilgiler olmalıdır

2. Bilgiler objektif güveniler ve tarafsız olmalıdır.

3. Bilgiler kamunun anlayabileceği düzeyde olmalıdır.

4. Bilgiler zamanlılık esasına uygun olarak açıklanmalı yani geçerliliğini kaybetmemeli.

5. Açıklanan bilgilerin tutarlılık (Consistency) ilkelerine bağlılı̆̆ esas almalıdır.

6. Kamuya açıklanan bilgilerin standart formla sunulması ve terminoloji birliğinin sağlanmış olması gereklidir

Ayrıca hesap verme, yönetim olgusunun özünde vardır ve kaynakları yöneten her kişi, kurum veya örgütsel birimin en temel yükümlülügüdür. Hesap verme yükümlülüğünün kamu yönetiminde tezahür etmesi demokrasiler açısından kaçınılmaz kabul edilmektedir. Çünkü kamu idarelerine tevdi edilen görevlerin yürütülmesi ve kamu kaynaklarının elde edilmesi ile kullanımı konularında halkın bilgi isteme ve hesap sorma hakkı demokrasilerin özünde yatan bir yetkidir. Hesap verme yükümlülüğü kamu yönetimleri bakımından bir çağdaşlık kriteri olarak da algılanmakta ve yönetimde çağdaşlık ile demokrasiyi buluşturmaktadır (Aksoy,2006:1). 5018 Sayılı Kamu Mali Yönetimi ve Kontrol Kanununda mali saydamlık başlığında (md 7) "Her türlü kamu kaynağının elde edilmesi ve kullanılmasında denetimin sağlanması amacıyla kamuoyu zamanında bilgilendirilir" ifadesi yer almaktadır. Ayrıca aynı Kanunun hesap verme sorumluluğu başlığında (md 8) "Her türlü kamu kaynağının elde edilmesi ve kullanılmasında görevli ve yetkili olanlar, kaynakların etkili, ekonomik, verimli ve hukuka uygun olarak elde edilmesinden, kullanılmasından, muhasebeleştirilmesinden, raporlanmasından ve kötüye kullanılmaması için gerekli önlemlerin alınmasından sorumludur ve yetkili kılınmış mercilere hesap vermek zorundadır" denilmektedir. Kanunun madde gerekçelerinde ise "Malî saydamlık, çağdaş kamu malî yönetiminin temel ilkelerindendir. Saydam bir kamu malî yönetim sisteminin oluşturulması, malî verilerin zamanında kamuoyuna açıklanması ve raporlanmasıyla mümkündür" denilmekte ve hesap verme ile ilgili olarak da "Çağdaş kamu malî yönetim sisteminin önemli unsurlarından biri olan hesap verebilirlik, kendilerine kamu gücü kullanma görev ve yetkisi verilenlerin bu yetkiyi yasal sınırlar içinde kullanıp kullanmadıklarının hesabını vermeleri anlamına gelmektedir. Bu çerçevede, kamu kaynaklarının etkili, ekonomik ve verimli bir şekilde elde edilmesi ve kullanılması, muhasebeleştirilmesi ve raporlanmasının sağlanması, ayrıca kötüye kullanımın önlenmesi için görevli ve yetkili olanların gerekli önlemlerin alınmasından sorumlu tutulması ve yetkili kılınmış mercilere bu Kanun hükümleri çerçevesinde hesap vermeleri öngörülmüştür” şeklinde ifade edilmektedir. Diğer yandan aynı Kanunun muhasebe sistemi ile ilgili olarak (md 49) "Muhasebe sistemi; karar, 
Şengel, S. (2017). Ticaret Odalarının web sitesi aracılığıyla kamuyu aydınlatmaları üzerine bir araştırma. International Journal of Social Sciences and Education Research, 3(2), 644-656.

kontrol ve hesap verme süreçlerinin etkili çalışmasını sağlayacak ve malî raporların düzenlenmesi ile kesin hesabın çıkarılmasına temel olacak şekilde kurulur ve yürütülür” olması belirtilmektedir. Kamu Mali Yönetimi ve Kontrolü Kanunu ile kurulacak muhasebe sisteminin yöneticilerin saydamlık ve hesap verebilirlik ilkelerine göre mali nitelikli işlemleri kayıt altına alıp, raporlamasını ve zamanlı ve güvenilir bir şekilde ilgililerine ve kamuoyuna duyurulmasını sağlayacak şekilde olması öngörülmektedir.

Diğer yandan saydam bir kamu mali yönetim sisteminin oluşturulması, mali verilerin zamanında kamuoyuna açıklanması ve raporlanmasıyla mümkündür(Erdoğan, 2007: 26).

Bu bağlamda Kamu kurumu niteliğinde bir meslek kuruluşu olarak tanımlanan ticaret odalarının kamuyu mali bilgileri konusunda kamuyu aydınlatması beklenir. Meslek kuruluşu yöneticilerinin mali durum ve raporları ile birlikte faaliyet raporu, stratejik plan, eğitim, yayın vb. konularda kamuoyu ile bilgi paylaşabilmelerinin bir yolu kesintisiz yayın yapabilen ekonomik ve etkili bir iletişim olanağ 1 veren web siteleridir.

\subsection{Bilgi Sunma Aracı Olarak Web Siteleri}

Son yıllardaki bilişim teknolojisinde gelişmeler ekonomik ve sosyal yaşamı etkilemiştir. Bu gelişmelerden biriside web siteleridir. Web siteleri kurum ve kuruluşlara yeni olanaklar sağlamıştır. Bu olanaklardan biriside etkili bir iletişim aracı olmasıdır.

Günümüzde web siteleri önemli bir bilgilendirme ve iletişim aracıdır. Üç tür web sitesinin varlı̆̆ından bahsedilebilir. Bunlar, tanıtım (presence), bilgi sağlama (informational) ve e-ticaret (e-commerce) modelleridir. Bu sitelerin özellikleri şöyle belirtilebilir (www.inet-tr.org.tr/inetconf9/sunum/35.ppt E.T 2.11.2016);

\section{-Tanitım (Presence) Modeli}

$\mathrm{Bu}$ tür sitelerde çok fazla bilgi bulunmamaktadır.

Kullanıcılar, özel bir bilgi almak istediklerinde bu sitelerle ilgilenmektedirler. Bu tür siteler küçük gruplar tarafından hazırlamaktadır ve dizayna özel olarak dikkat edilmemektedir.

\section{-Bilgi Sağlama (Informational) Modeli}

Bunlar bilgi ağılıklı sitelerdir. Sitenin sayfaları, bilgiler nedeniyle çok ağırdır. Özel olarak tasarlanmışlardır. Kullanıcıların sorularının cevaplandırıldığı kuruluş siteleridir.

\section{-E-ticaret (commerce) Modeli}

Bu siteler satışa dönük tasarlanmıştır. Alt yapısı ona göre hazırlanmıştır.

Günümüzün önemli iletişim aracı olarak web siteleri kolayca ulaşım olanağı, düşük maliyet sürekli yayında olma vb. özellikleriyle kurum ve kuruluşlara önemli bir olanak sağlamaktadır.

Günümüzde, kuruluşları web siteleri aracılığıyla üyelerine hizmet etme düzeyleri artmıştır. Kamu kurumlarının kamuyu bilgilendirici web siteleri yanında meslek kuruluşları ve odalarının da bilgilendirici web sitelerinin sayısı hızla artmaktadır. Bu bağlamda meslek odaları da web siteleri aracılığıyla bilgi sunumu gerçekleştirmektedirler. Odaların oluşturdukları bu siteler bilgi siteleri niteliğindedir. Bu siteleri oluşturma nedenleri işe şöyle sıralanabilir;

-Oda bilgi paylaşımı 
Şengel, S. (2017). A research on how Chambers of Commerce inform public through web sites. International Journal of Social Sciences and Education Research, 3(2), 644-656.

-Küresel iletişism olanağ 1

-Oda mensupları ile daha iyi iletişim

-İletişim masraflarından tasarruf

-Paylaşım, işbirliği,

-Güncel mevzuat hakkında bilgi,

-Ekonomik bilgilerin paylaşımı

-Eğitim bilgilerinin

-Yayınlar

-Oda üyelerinin görüşlerini alabilme vb. şeklinde sıralanabilir.

\section{Araştırma bilgileri}

\subsection{Araştırmanın amacı}

Araştırmanın amacı, Ticaret Odalarının, oda üyelerini ve diğer ilgili kişi ve kurumlar ile kamuoyunu web siteleri aracılığılla nasıl bilgilendirdikleri hakkında bilgi sunmaktır.

$\mathrm{Bu}$ araştırma, Ticaret odalarının bir hizmet sunma aracı olarak web sitelerini ne şekilde hazırladıklarını ve hangi hizmetleri sunduklarını, hizmet sunma aracı olarak web sitelerinin oynadığı rolü belirlemeyi amaçlamaktadır.

\subsection{Araştırma yöntemi}

Bilgiye ulaşım ve bilgiyi ulaştırma aracı olarak web sitelerinin oynadığı rol kalitatif araştırma yöntemlerinden biri olan içerik analizi yoluyla belirlenmesi amaçlanmıştır. İçerik çözümlemesi, sosyal gerçeğin yazılı/açık (manifest)içeriklerinin özelliklerinden yazılı/açık(manifest) olmayan içerik özellikleri hakkında çıkarımlar yapmak yoluyla sosyal gerçeği araştıran bir yöntemdir. (Gökçe,1995:24)

$\mathrm{Bu}$ araştırma web siteleri ziyaret edilerek geliştirilen bir değerlendirme formu üzerinde gerekli bilgilerin işaretlenmesi yoluyla yapılmıştır

\section{3. Örneklerin olușturulması}

Türkiye'deki 182 Ticaret ve Sanayi Odası ve 56 Ticaret Odası, 12 sanayi Odası ve 2 Deniz Ticaret Odası web siteleri ana kütle olarak seçilmiştir. Odaların bilgilerine TOBB web sitesinden ulaşılmıştır. İncelenen oda web siteleri şunlardır (E.T: 20.10.2016). 
Şengel, S. (2017). Ticaret Odalarının web sitesi aracılığıyla kamuyu aydınlatmaları üzerine bir araştırma. International Journal of Social Sciences and Education Research, 3(2), 644-656.

Tablo 1. İncelenen odaların web siteleri

\begin{tabular}{|c|c|c|c|}
\hline \multicolumn{4}{|c|}{ TICARET VE SANAYİ ODALARI (TSO) } \\
\hline 1-Adiyaman TSO & $\begin{array}{l}\text { http://www.adiya- } \\
\text { mantso.org.tr }\end{array}$ & $\begin{array}{l}\text { 92-Kahramanmaraş Tic. Ve } \\
\text { San. Oda. } \\
\end{array}$ & http://www.kmtso.org.tr/ \\
\hline 2-Afşin TSO & http://www.afsintso.org.tr/ & 93-Kaman TSO & http://www.kamantso.org.tr \\
\hline 3-Afyonkarahisar TSO & http://www.afyontso.org.tr/ & 94-Karabük TSO & http://www.karabuktso.org.tr/ \\
\hline 4-Ağrı TSO & http://www.agritso.org.tr & 95-Karacabey TSO & http://www.karacabeytso.com/ \\
\hline 5-Akçakoca TSO & $\begin{array}{l}\text { http://www.akcako- } \\
\text { catso.org.tr/ }\end{array}$ & 96-Karahallı TSO & ---- \\
\hline 6- Akhisar TSO & http://www.akhisartso.org.tr & 97-Karaman TSO & http://www.ktso.org.tr/ \\
\hline 7 Aksaray TSO & http://www.aksaraytso.org.tr & 98-Karapınar TSO & http://www.karapinartso.org.tr/ \\
\hline 8 Akşehir TSO & http://www.aksaraytso.org.tr & 99-Kars TSO & http://karstso.org.tr \\
\hline 9- Akyazı TSO & http://akyazitso.tobb.org.tr/ & 100-Kastamonu TSO & http://www.kastamonutso.org.tr/ \\
\hline 10- Alaca TSO & http://www.alacatso.org.tr & 101-Kelkit TSO & ---- \\
\hline 11- Alanya TSO & http://www.altso.org.tr & 102-Keşan TSO & http://www.kesantso.tobb.org.tr \\
\hline 12- Alaplı TSO & $\begin{array}{l}\text { http://www.alap- } \\
\text { litso.tobb.org.tr }\end{array}$ & 103-Kırıkhan TSO & $\begin{array}{l}\text { http://www.kirik- } \\
\text { hantso.tobb.org.tr }\end{array}$ \\
\hline 13 Alaşehir TSO & http://www.alasehirtso.com/ & 104-Kırıkkale TSO & http://www.kirikkaletso.org.tr/ \\
\hline 14 Amasya TSO & http://www.amasyatso.org.tr/ & 105-Kırklareli TSO & http://www.kirklarelitso.org.tr/ \\
\hline 15 Anamur TSO & http://www.anamurtso.org & 106-Kırşehır TSO & http://www.kirsehirtso.org.tr/ \\
\hline 16-Antakya TSO & http://www.antakyatso.org.tr/ & 107-Kızıltepe TSO & http://www.kiziltepetso.org.tr/ \\
\hline 17- Antalya TSO & http://www.atso.org.tr & 108-Kilis TSO & http://www.kilistso.tobb.org.tr/ \\
\hline 18-Ardahan TSO & http://www.ardahantso.org.tr & 109-Kumluca TSO & http://www.kumlucatso.org.tr \\
\hline 19- Ardeşen TSO & http://www.ardesentso.org.tr & 110-Kütahya TSO & http://www.kutso.org.tr/ \\
\hline 20- Arhavi TSO & http://www.arhavitso.org.tr & 111-Lüleburgaz TSO & http://www.ltso.org.tr/ \\
\hline 21- Artvin TSO & http://www.artvintso.org.tr/ & 112-Malatya TSO & http://www.malatyatso.org.tr/ \\
\hline 22- Babaeski TSO & http://www.babaeskitso.org.tr/ & 113- Malkara TSO & http://www.malkaratso.org.tr/ \\
\hline 23- Bafra TSO & http://www.bafratso.org.tr/ & 114-Manavgat TSO & http://www.matso.org.tr/ \\
\hline 24- Bartın TSO & http://www.bartintso.org.tr/ & 115-Manisa TSO & http://www.manisatso.org.tr \\
\hline 25- Batman TSO & http://www.batso.org.tr/ & 116-Mardin TSO & http://www.mardintso.tobb.org.tr/ \\
\hline 26 -Bayburt TSO & http://www.bayburttso.org.tr & 117-Mersin TSO & http://www.mtso.org.tr/ \\
\hline 27 -Biga TSO & $\begin{array}{l}\text { http://www.bi- } \\
\text { gatso.tobb.org.tr/ }\end{array}$ & 118-Merzifon TSO & $\begin{array}{l}\text { http://www.merzi- } \\
\text { fontso.tobb.org.tr }\end{array}$ \\
\hline 28- Bilecik TSO & http://bileciktso.org/ & 119-Milas TSO & http://mitso.org.tr/ \\
\hline 29- Bingöl TSO & http://www.bintso.org.tr/ & 120-Mucur TSO & ------ \\
\hline 30- Birecik TSO & http://www.bireciktso.org.tr/ & 121-Muğla TSO & http://www.mutso.org.tr/ \\
\hline 31- Bitlis TSO & http://www.bitlistso.org.tr/ & 122-Muş TSO & http://mustso.org.tr/ \\
\hline 32-Boğazlıyan TSO & --- & 123-Mustafakemalpaşa TSO & http://www.mkptso.org.tr \\
\hline 33- Bolu TSO & http://www.bolutso.org.tr/ & 124-Mut TSO & http://www.muttso.org.tr/ \\
\hline 34- Bolvadin TSO & http://www.bolvadintso.com/ & 125-Nevşehır TSO & http://www.ntso.org.tr/ \\
\hline 35- Bor TSO & http://www.bortso.tobb.org & 126-Niğde TSO & http://www.nitso.org.tr/ \\
\hline 36- Borçka TSO & $\begin{array}{l}\text { http://www.borc- } \\
\text { katso.tobb.org.tr/ }\end{array}$ & 127-Niksar TSO & http://www.niksartso.tobb.org.tr \\
\hline 37- Boyabat TSO & http://www.boyabattso.org.tr/ & 128-Nusaybin TSO & http://nusaybintso.org.tr/ \\
\hline 38- Bozüyük TSO & http://www.bozuyuktso.org.tr/ & 129-Of TSO & http://www.oftso.org.tr/ \\
\hline 39- Bucak TSO & http://www.bucaktso.org.tr/ & 130-Oltu TSO & http://www.oltutso.com/ \\
\hline 40- Bulancak TSO & $\begin{array}{l}\text { http://www.bulancak- } \\
\text { tso.org.tr/ }\end{array}$ & 131-Ordu TSO & http://www.otso.org.tr/ \\
\hline 41- Burdur TSO & http://www.burdurtso.com/ & 132-Orhangazi TSO & http://www.orhangazitso.org.tr/ \\
\hline 42- Bursa TSO & http://www.btso.org.tr/ & 133-Osmaniye TSO & http://www.osmaniyetso.org.tr/ \\
\hline 43- Çanakkale TSO & $\begin{array}{l}\text { http://www.canakka- } \\
\text { letso.org.tr/ }\end{array}$ & 134-Pasinler TSO & $\begin{array}{l}\text { http://www.pasin- } \\
\text { lertso.tobb.org.tr/ }\end{array}$ \\
\hline
\end{tabular}


Şengel, S. (2017). A research on how Chambers of Commerce inform public through web sites. International Journal of Social Sciences and Education Research, 3(2), 644-656.

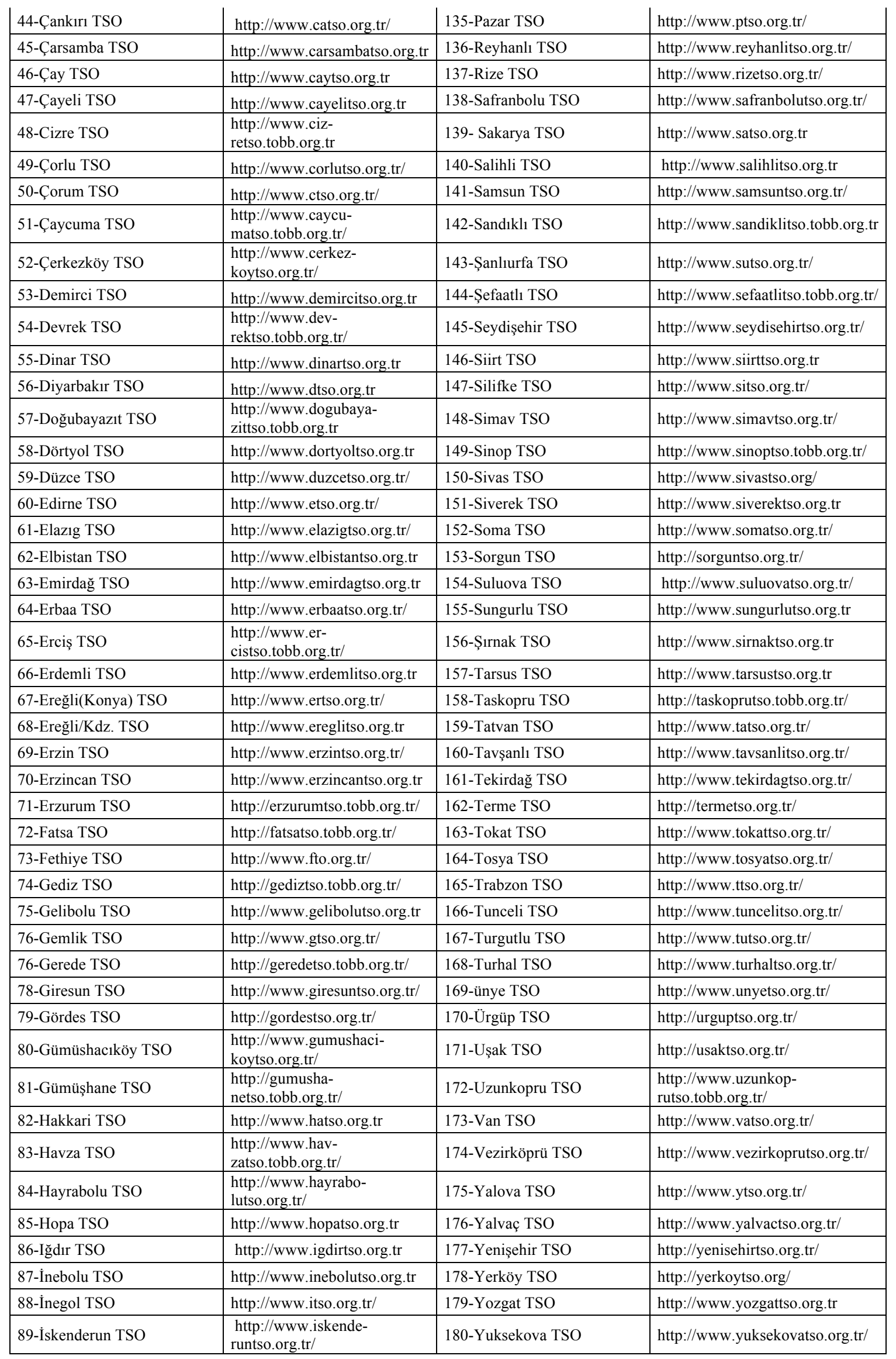


Şengel, S. (2017). Ticaret Odalarının web sitesi aracılığıyla kamuyu aydınlatmaları üzerine bir araştırma. International Journal of Social Sciences and Education Research, 3(2), 644-656.

\begin{tabular}{|c|c|c|c|}
\hline 90-Isparta TSO & http://www.itso.org/ & 181-Zile TSO & http://www.ziletso.org.tr/ \\
\hline 91--İznik TSO & http://www.izniktso.org.tr/ & 182-Zonguldak TSO & http://www.ztso.org.tr/ \\
\hline \multicolumn{4}{|c|}{ TICARET ODALARI } \\
\hline 1-Acipayam Ticaret Odası & $\begin{array}{l}\text { http://www.acipayamticareto- } \\
\text { dasi.org/ }\end{array}$ & 29-Gonen Ticaret Odas1 & http://www.gonento.tobb.org.tr/ \\
\hline 2-Adana Ticaret Odası & http://www.adana-to.org.tr & 30-Haymana Ticaret Odas & --------- \\
\hline 3-Aliağa Ticaret Odası & http://www.alto.org.tr/ & 31-Ilgın Ticaret Odası & http://www.ilginto.org.tr/ \\
\hline 4-Ankara Ticaret Odası & http://www.atonet.org.tr/ & 32-İslahiye Ticaret Odası & http://www.islahiyeto.org.tr/ \\
\hline 5-Aydın Ticaret Odası & http://www.ayto.org.tr/ & 33-İstanbul Ticaret Odas1 & http://www.ito.org.tr/wps/portal \\
\hline 6-Ayvalık Ticaret Odası & http://www.ayvalikto.org.tr/tr/ & 34-İzmir Ticaret Odası & http://www.izto.org.tr/tr/ \\
\hline 7-Babadağ Ticaret Odası & 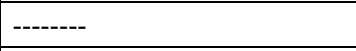 & 35-Kadirli Ticaret Odası & http://www.kadirlito.tobb.org.tr \\
\hline 8-Balıkesir Ticaret Odası & http://www.bato.org.tr/ & 36-Kayseri Ticaret Odası & http://www.kayserito.org.tr/ \\
\hline 9-Bandırma Ticaret Odası & http://www.bandirmato.org.tr & 37-Kocaeli Ticaret Odas1 & http://www.koto.org.tr/ \\
\hline 10-Bayındır Ticaret Odası & $\begin{array}{l}\text { http://www.bayin- } \\
\text { dirto.tobb.org.tr }\end{array}$ & 38-Konya Ticaret Odas1 & http://www.kto.org.tr/ \\
\hline 11-Bergama Ticaret Odası & http://www.berto.org.tr/ & 39-Kozan Ticaret Odası & http://kozanto.org/kto/ \\
\hline 12-Beypazarı Ticaret Odası & http://beypazarito.org.tr & 40-Körfez Ticaret Odas1 & http://www.korfezto.org.tr \\
\hline 13-Beyşehir Ticaret Odası & http://www.beysehirto.org.tr/ & 41-Kuşadası Ticaret Odası & http://www.kuto.org.tr/ \\
\hline 14-Bodrum Ticaret Odası & http://www.bodto.org.tr/ & 42-Marmaris Ticaret Odası & http://www.mto.org.tr/ \\
\hline 15-Buldan Ticaret Odası & $\begin{array}{l}\text { http://www.buldanticareto- } \\
\text { dasi.org.tr/ }\end{array}$ & 43-Menemen Ticaret Odası & $\begin{array}{l}\text { http://www.mene- } \\
\text { mento.tobb.org.tr }\end{array}$ \\
\hline 16-Bünyan Ticaret Odası & http://www.bunyanto.org.tr & 44-Nazilli Ticaret Odas1 & http://www.naztic.org.tr/ \\
\hline 17-Burhaniye Ticaret Odası & $\begin{array}{l}\text { http://www.burhani- } \\
\text { yeto.org.tr/ }\end{array}$ & 45-Nizip Ticaret Odası & http://www.nto.org.tr/ \\
\hline 18-Ceyhan Ticaret Odas 1 & http://www.ceyhanto.org.tr/ & 46-Ödemiş Ticaret Odası & http://www.odemisto.org.tr/ \\
\hline 19-Çumra Ticaret Odas1 & http://www.cumrato.org.tr/ & 47-Polatlı Ticaret Odas1 & http://www.pto.org.tr/ \\
\hline 20-Denizli Ticaret Odası & http://www.dto.org.tr/ & 48-Sarayköy Ticaret Odası & $\begin{array}{l}\text { http://www.saraykoyticareto- } \\
\text { dasi.org.tr/ }\end{array}$ \\
\hline 21-Devei Ticaret Odas1 & http://www.develito.org.tr & 49-Selçuk Ticaret Odası & $\begin{array}{l}\text { http://www.selcukticareto- } \\
\text { dasi.org.tr }\end{array}$ \\
\hline 22-Didim Ticaret Odas1 & http://www.didimto.org.tr/ & $\begin{array}{l}\text { 50-Şereflikochisar Ticaret } \\
\text { Odası }\end{array}$ & $\begin{array}{l}\text { http://www.sereflikochi- } \\
\text { sarto.org.tr/ }\end{array}$ \\
\hline 23-Doğanhisar Ticaret Odası & $\begin{array}{l}\text { http://www.doganhi- } \\
\text { sarto.org.tr/ }\end{array}$ & 51-Söke Ticaret Odası & http://www.sto.org.tr/ \\
\hline 24-Edremit Ticaret Odas1 & $\begin{array}{l}\text { http://www.edremit- } \\
\text { to.org.tr/tr/ }\end{array}$ & 52-Susurluk Ticaret Odas1 & http://www.susurlukto.org.tr/tr/ \\
\hline 25-Erdek Ticaret Odas1 & $\begin{array}{l}\text { http://www.er- } \\
\text { dekto.tobb.org.tr/index.htm }\end{array}$ & 53-Tavas Ticaret Odası & http://www.tavasto.org.tr/ \\
\hline 26-Eskişehir Ticaret Odası & http://www.etonet.org.tr/ & 54-Tire Ticaret Odas 1 & http://www.tireto.org.tr/tr/ \\
\hline 27-Gaziantep Ticaret Odası & http://www.gto.org.tr & 55-Torbalı Ticaret Odası & http://www.torbalito.tobb.org.tr/ \\
\hline 28-Gebze Ticaret Odası & http://gebzeto.org.tr/ & 56-Yahyalı Ticaret Odası & http://yahyalito.org.tr/ \\
\hline \multicolumn{4}{|c|}{ SANAYI ODALARI } \\
\hline 1-Adana Sanayi Odası & http://www.adaso.org.tr & 7-Eskişehir Sanayi Odası & http://www.eso.org.tr/ \\
\hline 2-Ankara Sanayi Odası & http://www.aso.org.tr & 8-Gaziantep Sanayi Odası & http://www.gso.org.tr/ \\
\hline 3-Aydın Sanayi Odası & http://www.ayso.org.tr/ & 9-İstanbul Sanayi Odası & http://www.iso.org.tr/ \\
\hline 4-Balıkesir Sanayi Odası & http://www.bso.org.tr/ & 10-Kayseri Sanayi Odas1 & http://www.kayso.org.tr/ \\
\hline 5-Denizli Sanayi Odası & http://www.dso.org.tr/ & 11-Kocaeli Sanayi Odas1 & http://www.kosano.org.tr/ \\
\hline 6-Ege Bölgesi Sanayi Odası & http://www.ebso.org.tr/ & 12-Konya Sanayi Odası & http://www.kso.org.tr/ \\
\hline \multicolumn{4}{|c|}{ DENIZ TICARET ODALARI } \\
\hline $\begin{array}{l}\text { İMEAK Deniz Ticaret Odası } \\
\text { (7 Şube) }\end{array}$ & $\begin{array}{l}\text { http://www.denizticareto- } \\
\text { dasi.org.tr/ }\end{array}$ & Mersin Deniz Ticaret Odası & http://mdto.org.tr/ \\
\hline
\end{tabular}

\section{Araştırma bulguları}

Ticaret ve Sanayi Odaları, Ticaret Odaları, Sanayi Odaları, Deniz Ticaret Odaları, mali raporlar, (bilanço ve gelir tablosu), faaliyet raporu, stratejik plan, eğitim ve yayın başlıkları altında incelenmiştir. Muhasebe temel mali tablolar olarak bilanço ve gelir tablosu ifade edilmektedir. 
Şengel, S. (2017). A research on how Chambers of Commerce inform public through web sites. International Journal of Social Sciences and Education Research, 3(2), 644-656.

Ancak web siteleri incelendiğinde bazı odaların gelir- gider tabloları, mizan yayınladıkları görülmüştür. Bu nedenle incelemeye ayrı bir başlık olarak mizanda eklenmiştir. Araştırmada yüzde analizi yapılmıştır.

\subsection{Ticaret ve Sanayi Odalart mali bilgileri}

Ticaret ve Sanayi Odaları web siteleri oda mali bilgileri sunumu açısından incelenmiştir. Ticaret ve Sanayi Odaları web siteleri incelendiğinde ( 182 oda) Tablo-2'de görüldüğü gibi odaların sadece 1 tanesi (\%0.55) bilanço, 5 oda gelir-gider tablosu (\% 2.74) ve 2 oda mizan (\%1.10) yayınlamıştır. Diğer odalar bilanço, gelir tablosu bilgilerini web sitelerinde yayınlamadığ müştür. Diğer bir deyişle odaların yaklaşık \% 98 oda mali bilgileri konusunda kamuya yeterli bilgi sunmamıştır.

Tablo 2. Ticaret ve Sanayi Odaları mali bilgileri

\begin{tabular}{|c|c|c|c|c|c|}
\hline \multirow{2}{*}{ Değişkenler } & \multirow{2}{*}{ Toplam Frekans } & \multicolumn{2}{|c|}{ Var } & \multicolumn{2}{c|}{ Yok } \\
\cline { 3 - 6 } & & Frekans & \% & Frekans & $\%$ \\
\hline Bilanço & 182 & 1 & 0.55 & 181 & 99.45 \\
\hline Gelir-Gider Tablosu & 182 & 5 & 2.74 & 177 & 97.26 \\
\hline Mizan & 182 & 2 & 1.10 & 181 & 98.90 \\
\hline
\end{tabular}

\subsection{Ticaret Odaları mali bilgileri}

Ticaret Odaları web siteleri oda mali bilgi sunumu açısından incelendiğinde Tablo 3'te görüldüğü gibi odaların web sitelerinin çoğunluğunda oda mali bilgilerine yer verilmemiştir. 56 ticaret odasından sadece 2 oda bilanço ve gelir tablosunu, bir oda mizanı web sitesinde yayınlamıştır Diğer odalar bilanço, gelir tablosu ve mizan bilgilerine web sitesinde yer vermemiştir.

Tablo 3. Ticaret Odaları mali bilgileri

\begin{tabular}{|c|c|c|c|c|c|}
\hline \multirow{2}{*}{ Değişkenler } & \multirow{2}{*}{ Toplam Frekans } & \multicolumn{2}{|c|}{ Var } & \multicolumn{2}{c|}{ Yok } \\
\cline { 3 - 6 } & & Frekans & \% & Frekans & \% \\
\hline Bilanço & 56 & 2 & 3.57 & 54 & 96.43 \\
\hline Gelir Tablosu & 56 & 2 & 3.57 & 54 & 96.43 \\
\hline Mizan & 56 & 1 & 0.02 & 55 & 99.98 \\
\hline
\end{tabular}

\subsection{Sanayi ile Deniz Ticaret Odaları mali bilgileri}

Sanayi 12 (oda) ile Deniz Ticaret Odaları (2 oda) web siteleri oda mali bilgi sunumu açısından incelendiğinde Tablo 4'te görüldüğ̈̈ gibi sadece 3 oda ( \%21.42) gelir -gider tablosuna yer vermişken diğer odaların tümü, web sitelerinde bilanço, gelir-gider tablosu ve mizan bilgilerine yer vermemiştir.

Tablo 4. Sanayi ile Deniz Ticaret Odaları mali bilgileri

\begin{tabular}{|c|c|c|c|c|c|}
\hline \multirow{2}{*}{ Değişkenler } & \multirow{2}{*}{ Toplam Frekans } & \multicolumn{2}{|c|}{ Var } & \multicolumn{2}{c|}{ Yok } \\
\cline { 3 - 6 } & & Frekans & $\%$ & Frekans & $\%$ \\
\hline Bilanço & 14 & - & - & 14 & 100 \\
\hline Gelir -Gider Tablosu & 14 & 3 & 21.42 & 11 & 78.58 \\
\hline Mizan & 14 & - & - & 14 & 100 \\
\hline
\end{tabular}


Şengel, S. (2017). Ticaret Odalarının web sitesi aracılığıyla kamuyu aydınlatmaları üzerine bir araştırma. International Journal of Social Sciences and Education Research, 3(2), 644-656.

\subsection{Ticaret ve Sanayi Odaları faaliyet raporu, stratejik plan ve mali politika bilgileri}

Ticaret ve Sanayi Odaları web siteleri, Faaliyet Raporu, Stratejik Plan ve Mali Politika Bilgileri sunumu açısından incelendiğinde Tablo 5 'te görüldüğü gibi odaların yaklaşı \% 42'si faaliyet raporu (75 oda) ve stratejik (77 oda) planlarını kamuoyuna sunmuştur. Geriye kalan \% 58 oda faaliyet raporu ve stratejik planını kamuoyuna sunmamıştır. Diğer yandan mali politika bilgilerini yaklaşı (38 oda) \%20'si web sitesinde kamuoyuna sunarken geri kalan \% 80 bu bilgiyi paylaşmamıştır.

Tablo 5. Ticaret ve Sanayi Odaları faaliyet raporu, stratejik plan ve mali politika bilgileri

\begin{tabular}{|c|c|c|c|c|c|}
\hline \multirow{2}{*}{ Değişkenler } & \multirow{2}{*}{ Toplam Frekans } & \multicolumn{2}{|c|}{ Var } & \multicolumn{2}{c|}{ Yok } \\
\cline { 3 - 6 } & & Frekans & \% & Frekans & $\%$ \\
\hline Faaliyet Raporu & 182 & 75 & 41.20 & 107 & 58.80 \\
\hline Stratejik Plan & 182 & 77 & 42.30 & 105 & 57.70 \\
\hline Mali Politika & 182 & 38 & 20.87 & 143 & 79.13 \\
\hline
\end{tabular}

\subsection{Ticaret Odaları faaliyet raporu, stratejik plan ve mali politika bilgileri}

Ticaret Odaları web siteleri, Faaliyet Raporu, Stratejik Plan ve Mali Politika Bilgileri sunumu açısından incelendiğinde Tablo 6' da görüldüğü gibi odaların \% 44.64 (25 oda) faaliyet raporunu, \% 57.14 (32 oda) stratejik planını, \% 53.57 ( 30 oda) mali politikasını yayınlamıştır. Diğer odalar faaliyet raporu ( 31 oda \% 55.36), stratejik plan ( 24 oda, $\% 42.86$ ) ve mali politika ( 26 oda \% 46.43) bilgilerine web sitelerinde yer vermemiştir.

Tablo 6. Ticaret Odaları faaliyet raporu, stratejik plan ve mali politika bilgileri

\begin{tabular}{|c|c|c|c|c|c|}
\hline \multirow{2}{*}{ Değişkenler } & \multirow{2}{*}{ Toplam Frekans } & \multicolumn{2}{|c|}{ Var } & \multicolumn{2}{c|}{ Yok } \\
\cline { 3 - 6 } & & Frekans & \% & Frekans & \% \\
\hline Faaliyet Raporu & 56 & 25 & 44.64 & 31 & 55.36 \\
\hline Stratejik Plan & 56 & 32 & 57.14 & 24 & 42.86 \\
\hline Mali Politika & 56 & 30 & 53.57 & 26 & 46.43 \\
\hline
\end{tabular}

\subsection{Sanayi ile Deniz Ticaret Odalarl faaliyet raporu, stratejik plan ve mali politika bilgileri}

Sanayi ile Deniz Ticaret Odaları web siteleri, Faaliyet Raporu, Stratejik Plan ve Mali Politika Bilgileri sunumu açısından incelendiğinde Tablo 7'de görüldüğü gibi odaların tamamı faaliyet raporu, stratejik plan ve mali politika bilgilerine web sitelerinde yer vermiştir.

Tablo 7. Sanayi ile Deniz Ticaret Odaları faaliyet raporu, stratejik plan ve mali politika bilgileri

\begin{tabular}{|c|c|c|c|c|c|}
\hline \multirow{2}{*}{ Değişkenler } & \multirow{2}{*}{ Toplam Frekans } & \multicolumn{2}{|c|}{ Var } & \multicolumn{2}{c|}{ Yok } \\
\cline { 3 - 6 } & & Frekans & \% & Frekans & $\%$ \\
\hline Faaliyet Raporu & 14 & 14 & 100 & - & - \\
\hline Stratejik Plan & 14 & 14 & 100 & - & - \\
\hline Mali Politika & 14 & 14 & 100 & - & - \\
\hline
\end{tabular}


Şengel, S. (2017). A research on how Chambers of Commerce inform public through web sites. International Journal of Social Sciences and Education Research, 3(2), 644-656.

\subsection{Ticaret ve Sanayi Odaları eğitim ve yayın bilgileri}

Ticaret ve Sanayi Odaları web siteleri, eğitim ve yayın bilgileri sunumu açısından incelendiğinde Tablo 8'da görüldüğü gibi odaların \%27.47 (50 oda) eğitim bilgisine ,\% 36.26 ( 66 oda ) yayın bilgilerine yer vermiştir. Odaların önemli bir kısmı eğitim ve yayın bilgilerine yer vermemiştir.

Tablo 8. Ticaret ve Sanayi Odaları eğitim ve yayın bilgileri

\begin{tabular}{|c|c|c|c|c|c|}
\hline \multirow{2}{*}{ Değişkenler } & \multirow{2}{*}{ Toplam Frekans } & \multicolumn{2}{|c|}{ Var } & \multicolumn{2}{c|}{ Yok } \\
\cline { 3 - 6 } & & Frekans & \% & Frekans & \% \\
\hline Eğitim & 182 & 50 & 27.47 & 132 & 72.53 \\
\hline Yayın & 182 & 66 & 36.26 & 116 & 63.74 \\
\hline
\end{tabular}

\subsection{Ticaret Odaları eğitim ve yayın bilgileri}

Ticaret Odaları web siteleri, eğitim ve yayın bilgileri sunumu açısından incelendiğinde Tablo 9'da görüldüğü gibi odaların yarısı eğitim ve yayın bilgilerine yer verirken diğer yarısını web sitelerinde bu bilgilere yer vermemiştir.

Tablo 9. Ticaret Odaları eğitim ve yayın bilgileri

\begin{tabular}{|c|c|c|c|c|c|}
\hline \multirow{2}{*}{ Değişkenler } & \multirow{2}{*}{ Toplam Frekans } & \multicolumn{2}{|c|}{ Var } & \multicolumn{2}{c|}{ Yok } \\
\cline { 3 - 6 } & & Frekans & \% & Frekans & \% \\
\hline Eğitim & 56 & 29 & 51.78 & 27 & 48.22 \\
\hline Yayın & 56 & 28 & 50.00 & 28 & 50.00 \\
\hline
\end{tabular}

\subsection{Sanayi ile Deniz Ticaret Odaları eğitim ve yayın bilgileri}

Sanayi ile Deniz Ticaret Odaları web siteleri, eğitim ve yayın bilgileri sunumu açısından incelendiğinde Tablo 10'da görüldüğü gibi odaların \% 71.42 (10 oda) eğitim bilgisine, \% 78.57 (11 oda) yayın bilgisine yer vermiş olup diğer odalar bu bilgilere yer vermemiştir.

Tablo 10. Sanayi ile Deniz Ticaret Odaları eğitim ve yayın bilgileri

\begin{tabular}{|c|c|c|c|c|c|}
\hline \multirow{2}{*}{ Değişkenler } & \multirow{2}{*}{ Toplam Frekans } & \multicolumn{2}{|c|}{ Var } & \multicolumn{2}{c|}{ Yok } \\
\cline { 3 - 6 } & & Frekans & \% & Frekans & \% \\
\hline Eğitim & 14 & 10 & 71.42 & 4 & 28.58 \\
\hline Yayın & 14 & 11 & 78.57 & 3 & 21.43 \\
\hline
\end{tabular}

\section{Sonuç}

Türkiye'de 182 Sanayi ve Ticaret Odası ile 56 Ticaret odası bulunmaktadır. Ayrıca 12 sanayi odası ve 2 Deniz Ticaret Odası vardır. Odalar kamu kurumu niteliğinde meslek odaları niteliğindedir. Odaların web siteleri, kamuyu aydınlatma açısından incelenmiştir. İncelemede kriter olarak bilanço ve gelir tablosu, faaliyet raporu, stratejik plan, eğitim ve yayınlar ele alınmıştır. Kamuyu aydınlatma açısından bu kriterlere göre odaların web sitelerinde mali bilgilere yeterli düzeyde yer vermedikleri, çok az düzeyde odanın mali bilgileri paylaştığı görülmektedir. Bazı odaların gelir gider tablosu yayınladıkları, bazı odaların ise mizanı yayınladıkları görülmektedir. 
Şengel, S. (2017). Ticaret Odalarının web sitesi aracılığıyla kamuyu aydınlatmaları üzerine bir araştırma. International Journal of Social Sciences and Education Research, 3(2), 644-656.

Diğer yandan odaların stratejik plan, faaliyet raporu ve mali politik bakımından web siteleri incelendiğinde ticaret ve sanayi odaları, ticaret odalarının yaklaşık yarısının, sanayi odaları ile deniz ticaret odalarının ise tamamının bu bilgileri web sitesinde kamuoyu ile paylaştığı görülmektedir.

Oda web siteleri eğitim ve yayın açısından incelendiğinde ise ticaret odalarının yaklaşık yarısı eğitim ve yayın konusunda bilgilere web sitelerinde yer vermektedir. Sanayi odaları ile deniz ticaret odaları ise eğitim ve yayın konusunda yaklaşık \% 75 oranında web sitelerinde bilgiye yer vermektedirler.

Odaların web sitelerini daha etkin ve erimli kullanma olanakları bulunmaktadırlar. Burada oda üyelerine ve kamuoyuna oda faaliyetleri hakkında daha fazla bilgi sunmaları olanaklıdır. Ancak bu olanaktan tam olarak yararlandıklarını söylemek güçtür. Sadece sanayi odaları ile deniz ticaret odalarının tamamı stratejik plan ve faaliyet raporlarını web sitesi aracılığıyla kamuoyu ile paylaşmıştır.

Odaların kamu kurumu niteliğinde meslek kuruluşu ve aynı zamanda ekonomik yaşamda önemli bir rolü olan kuruluşlar olarak web sitelerinden daha etkin ve verimli bir şekilde yararlanmalarında, kamuoyunu bilgilendirmelerinde yarar vardır.

\section{Kaynakça}

Aksoy, M (2006). 5018 Sayılı Kamu Mali Yönetimi Ve Kontrol Kanunu'na Göre Kamu Kaynağının Elde Edilmesinde Görevli Ve Yetkili Olanların Hesap Verme Sorumluluğu, Yaklaşım Dergisi, Sayı: 164, Ağustos.

Erdoğan, İ. (2007). İtibar, Kamu Mali Yönetiminde Malı Saydamlık Ve 5018 Sayılı Kamu Mali Yönetimi ve Kontrol Kanunu Çerçevesinde Değerlendirilmesi, Bütçe Dünyası Sayı 24, www.debud.org/Html/dergi/24/1tbar.pdf 12.04.2009

Eroğlu, C.A. (2003). Kurumsal Yönetim Illkeleri Çerçevesinde Kamunun Aydınlatılması, Sermaye Piyasası Kurulu, Yeterlik Etüdü, Ankara

Gökçe, O. (1995). İ̧erik Çözümlemesi, Selçuk Üniversitesi Yayınları, Konya, s.24

Kepekçi, (1983). Celal, Sermaye Piyasasının Gelişmesinde Muhasebenin Rolü, Anadolu Üniversitesi Yayınları, Y. No:6, İ.İ.B.F yayınları Y.No:2, Eskişehir

Tetik, N. \& Demirel, B. (2002). ................., Yaklaşım Dergisi, Ekim, Sayı 118, 2002

5018 Sayılı Kamu Mali Yönetimi ve Kontrol Kanununda

5018 Sayılı Kamu Mali Yönetimi ve Kontrol Kanunu Tasarısının Genel Gerekçeleri

www.inet-tr.org.tr/inetconf9/sunum/35.ppt E.T 2.11.2016 
Şengel, S. (2017). A research on how Chambers of Commerce inform public through web sites. International

Journal of Social Sciences and Education Research, 3(2), 644-656.

\section{Extended abstract in English}

Technological developments and especially the developments in the information technology in the recent years lead to important changes in the human and community lives. The developments in information technology made access to information no longer a problem and ensured rapid spreading and conveying of the information. The media that makes it possible for the information to spread and to be conveyed in the fastest sort of way today is internet environment and especially the websites.

The concept of enlightening the public inheres to explain a situation or inform about a situation, event or activity. Moreover, rendering account lies at the bottom of management phenomenon and it is the major obligation of any person, institution or organizational unit managing the resources. Appearance of the obligation of being accountable to public in public administration is regarded as inevitable in democracies. Because public's right to inquire about the performance of the tasks commended to public administrations and obtainment and usage of public resources and to call them to account is an authorization which is immanent in democracies. The expression of "the public shall be informed on time in order to make the auditing possible with regard to obtainment and usage of public resources of any nature" is stated under the title of Financial Transparency (Article 7) in the Public Finance Management and Control Law no. 5018. Moreover, it is stated that "They who are entrusted with and given the authority for the obtainment and usage of public resources of any nature effectively, economically, efficiently and legally are responsible for obtaining, using, accounting, reporting and taking due precautions to prevent them being misused and they are obliged to answer to competent authorities" under the title of Accountability (Article 8) of the same law. Within this scope it is also stated that "it is set forth to consider the people who are commissioned and authorized responsible to render the obtainment, usage, accounting and reporting of the public resources possible in an effective, economic and efficient way and to prevent them being misused and to answer to competent authorities within the scope of the provisions of this law". On the other hand, Article 49 of the same law regarding the accounting system states that "The Accounting System shall be established and carried out to form a basis to make it possible for the decision, control and accountability processes be effective and to compile financial reports and to prepare the final account.

In this context, it is expected for the chambers of commerce which are defined as public professional organizations to enlighten the public with respect to their financial information. Chambers of commerce are public trade organizations established to provide the business activities of their members to be conducted in an order and to perform the services stated in the law. Traders and industrialists registered to trade registry are obliged to be affiliated with the chambers. The members should pay the registry fee and yearly contribution to the chamber. Chambers are an important actor of business life and using a serious amount or resources when performing this task is a point in question. Due precautions were taken to enlighten the public with regard to private and public sectors on a legal basis today. One of the medias for the directors of professional organizations to share information with the public regarding their financial status and reports as well as their activity reports, strategic plans and opinions on training, publications etc. is the websites which convey information uninterruptedly and enable them to communicate economically and effectively.

Being an important media today, the websites provide an opportunity for the institutions and organizations with their features such as easy access, low cost, uninterrupted availability etc. The 
Şengel, S. (2017). Ticaret Odalarının web sitesi aracılığıyla kamuyu aydınlatmaları üzerine bir araştırma. International Journal of Social Sciences and Education Research, 3(2), 644-656.

performance level of institutions to serve their members have increased due to the websites. The number of websites belonging to public institutions to inform the public and informative websites of professional organizations and chambers spikes up. In this context, professional chambers are providing information via their websites. These sites made by chambers serve as informational sites.

The aim of the research is to provide information regarding how Chambers of Commerce inform the members of the chamber, other relevant people and institutions and the public via their websites. This research was made by marking the necessary information on an assessment form developed by visiting websites.

There are 182 Chambers of Industry and Commerce and 56 Chambers of Commerce in Turkey. There are also 12 Chambers of Industry and 2 Chambers of Shipping. Chambers are professional organizations with public institution status. Websites of the chambers are examined from the point of view of their ability to enlighten the public. The criteria used in the research are balance sheets and income statements, activity reports, strategic plan, trainings and publications. It is observed that the chambers don't give sufficient place to financial information on their websites to enlighten the public with respect to the criteria and only a limited number of chambers share the financial information of the chamber. While some chambers post their profit and loss account statements, some others post their trial balance only.

On the other hand, when the websites are examined in terms of their strategic plans, activity reports and financial policies, it is observed that almost half of the chambers of industry and commerce and chambers of commerce and all of the chambers of industry and chambers of shipping share this information with public on their websites.

When the websites of chambers are examined in terms of training and publications, it is observed that almost half of the chambers of commerce post information regarding training and publications on their websites. Approximately $75 \%$ of the chambers of industry and chambers of shipping share information regarding training and publications on their websites.

There are possibilities for the chambers to use their websites more effectively and efficiently. It is possible for them to provide more information about the activities of the chamber to their members and to the public. But it is rather hard to say that they entirely benefit from this possibility. Only all the chambers of industry and shipping shared their strategic plans and activity reports with public via their websites.

It would be beneficial for the chambers which are professional organizations with public institution status having an important role in economic life to more effectively and efficiently benefit from their websites and inform the public. 